\title{
Interregional Transfer of Carbon Emissions and Shared Responsibility: A Review of Theory and Evidence
}

\author{
Yabei $\mathrm{Hu}^{1} \&$ Yang $\mathrm{Tao}^{1}$ \\ ${ }^{1}$ School of International Economics and Trade, Nanjing University of Finance and Economics, Nanjing, China \\ Correspondence: Yabei Hu, School of International Economics and Trade, Nanjing University of Finance and \\ Economics, 3 Wenyuan Road, Xianlin College Town, Nanjing, China. E-mail: huyabei@nufe.edu.cn
}

Received: June 4, 2018

doi:10.5539/ijbm.v13n8p236
Accepted: June 26, 2018

Online Published: June 30, 2018

URL: https://doi.org/10.5539/ijbm.v13n8p236

\begin{abstract}
Addressing global climate change through obligation assignment of region-specific emissions reduction needs to measure not only direct carbon emissions of a particular region but also indirect carbon emissions, which are increasingly raised by interregional transfer of carbon emissions. With the literature on carbon emissions expanding substantially, emission transfers at both international and national levels have attracted a growing attention in the past years. This study provides an overview of the theoretical basis for, and empirical evidence on interregional emission transfers from three perspectives: transfer levels, transfer drivers and shared responsibility. We emphasize the contribution of such research to our understanding of global carbon emissions and regional responsibilities of emissions reduction. The discrepancies with previous studies are discussed in relation to the various theoretical arguments and empirical methods. Finally, based on the literature review, the study discusses theoretical and practical implications for scholars and practitioners, and highlights possible new directions for future research.
\end{abstract}

Keywords: interregional emission transfer, transfer drivers, shared responsibility

\section{Introduction}

The 2015 Paris Agreement calls for international community to pursue efforts to limit global-mean temperature rise by reducing carbon dioxide emissions. The Carbon emissions issue is first examined by environmental scientists who are interested in the greenhouse effect of carbon emissions (Fourier, 1824; Tyndall, 1859). Moving to a low carbon economy have attracted economists to explore the economic characteristics of carbon emissions since the late 20th century. Grossman and Krueger (1991) argue the environmental Kuznets curve (EKC) to hypothesize relationship between $\mathrm{CO}_{2}$ emissions and per capita real GDP. Copeland and Taylor (1995a, 1995b) propose the pollution haven hypothesis $(\mathrm{PHH})$, which analyzes pollution transfer among nations in free trade.

Economic globalization has pushed countries into the internationalization process through specialist production and global consumption. Due to resource endowments, industrial scale, production efficiency, and technological differences among countries, the issue of carbon transfer triggered by international trade and international industrial transfer plays a crucial role in global carbon emissions. The research on emission transfer is normally integrated with carbon footprint (Minx et al., 2009; Dong \& Geng, 2012; Pang et al., 2017), embodied carbon (Kainuma, Matsuoka \& Morita, 2000; Qi et al., 2014; Zhang et al., 2017), or carbon leakage (Babiker, 2005; Kuik \& Hofkes, 2010). As the importance of cross-regional trade and industrial transfer within a country is increasing recognized in the international climate change discussion, there is a growing literature on the carbon transfer within a nation as well (Yao \& Liu, 2010; Zhang, 2016; Liao \& Xiao, 2017).

To provide a more reasonable integrated framework to deal with perceived carbon emissions accounting worldwide, problems of emission transfer should be discussed firstly - How to define and measure the emission transfer at international or national levels in order to assess the total carbon emissions of certain regions? How to find and understand the factors that drive interregional transfer of carbon emissions? How to distribute and evaluate carbon emissions responsibilities among regions? In recent years, there has been considerable progress in studies of carbon transfer to answer the above questions. With various motivations, theoretical hypothesis and estimation methods, the present studies have not provided definite conclusions about emission transfers. It is then necessary to perform a survey of interregional transfer of carbon emissions in order to clarify current theoretical and empirical debate and provide a way of more systematically analyzing carbon emissions. 
The objective of this study is, firstly, to survey the theory and evidence on interregional emission transfers to obtain a comprehensive assessment of carbon emissions, secondly, to distinguish main factors driving interregional emission transfer in a non-cooperative globalized world and, finally, to provide a comparison of emission responsibilities based on different principles, including producer responsibility, consumer responsibility and shared responsibility.

The remainder of the paper is organized as follows. Section 2 describes interregional transfers of carbon emissions at both international and national levels. Section 3 describes interregional carbon transfer drivers and corresponding research methods. Section 4 presents responsibilities of carbon emissions. Finally, conclusions and implications are discussed in section 5 .

\section{Interregional Carbon Emission Transfer}

\subsection{Carbon Emission Transfer across Nations}

The principle of carbon emissions, established by the United Nations Framework Convention on Climate Change (UNFCCC) and the Kyoto Protocol, ignores the effect of carbon emission transfers. As a result, the transfer of emissions, or so-called carbon leakage, from one national inventory to another would weaken the effectiveness of global carbon emission reduction policies. Global climate governance in the post-Kyoto era need to pay more attention to the allocation of carbon emissions and emission reduction responsibilities with emission transfers taken into account. Generally, carbon emission transfers among various countries have been vented through the economic transmission mechanisms of international trade and investment. A large number of studies have estimated the transfer of emissions associated with the trade of non-renewable energy and carbon-intensive goods, and the relocation of heavy pollution industries, from high-income to low-income countries (Wyckoff \& Roop, 1994; Peters \& Hertwich, 2008a). The current literature is largely divided into three levels: macro-, meso-, and micro-levels of analysis.

At the macro-level of national economy, date from one country or multiple countries are used to perform Computable General Equilibrium (CGE) to study the impact of changes in socio-economic structure on carbon emissions or to evaluate resource use related to trade balances between countries (Kainuma, Matsuoka, \& Morita, 2000; Qi et al., 2014). Applying the pollution haven hypothesis (PHH) to carbon emissions analysis can be divided into two parts. On the one hand, there are significant differences in environmental management capabilities and environmental standards among countries. In the process of pursuing profit maximization, polluting energy-intensive industries or enterprises consider the cost of environmental control and continue to move from countries with stringent environmental protection laws to those with more relaxed environmental protection laws. This is known as the industrial flight hypothesis proposed by Tobey (1990). On the other hand, in order to promote exports or obtain investment to promote economic growth, some countries set pollution control standards lower than the social efficient level to attract the transfer of carbon-intensive industries, which is the pollution displacement hypothesis put forward by Liddle (2001). Obviously, according to PHH, whether for the pressure of governance cost considerations or the pursuit of an appeal for economic growth, carbon-intensive industries are transferred from developed countries to developing countries, thus revealing that developing countries encounter the risk of becoming a global carbon shelter. Research on carbon transfer mainly focuses on the analysis of the amount of embodied carbon transfer among countries in international trade.

At the meso-level of industrial economy, the industrial association analysis is used to quantitatively study the transfer of emissions in industrial sectors. Environmentally extended input-output analysis (EE-IOA) is currently the mainstream method for studying the carbon emission transfer. This input-output method can clearly calculate the trade and regional carbon emissions, including Single Regional Input-output (SRIO), Bilateral Region Input-output (BTIO) and Multi-Region Input-output (MRIO). The SRIO model uses the input-output table of a country to analyze the carbon emissions of the country. When considering the country's trade with other partners, this SRIO does not distinguish different trading partner countries. It is assumed that the production technology of the country and the trading partner country is the same, that is, the SRIO follows import substitution assumptions with the same energy consumption factor for imported products and domestic products. The SRIO model is relatively simple because of its calculation method and data requirements, which facilitates timely measurement of the embodied carbon emissions of a country, but the accuracy of the results is not high (Lin \& Polenske, 1995; Peters et al., 2007; Cao \& Xie, 2007; Dong \& Geng, 2012). Unlike the SRIO model, both the BTIO and the MRIO models are based on heterogeneous assumptions of domestic and foreign energy consumption. The BTIO model mainly considers bilateral trade and is widely used for the calculation of the transfer of carbon emissions among specific trading partners (Peters \& Hertwich, 2008a; Li \& Qi, 2010; Ren et al., 2014). The BTIO model does not consider the supply chain relationship of the inter-industry sectors under open conditions and assumes 
that all imported goods are ultimately consumed in the importing country, rather than the use for intermediate inputs, processing or re-export through the importing country. In contrast, the MRIO model further differentiates between imports for intermediate inputs and imports for final demand, which can cover the indirect effects of production activities on the supply chain and portray spillover effects and feedback effects among countries due to trade. The MRIO model is more suitable for calculating the environmental responsibility caused by the final consumption. However, the complexity of the model raises higher requirements for data processing and information support (Shui \& Harriss, 2006; Li \& Hewitt, 2008; Peters et al., 2007; Qi et al., 2014).

Different from the top-down approach of macro- and meso-level research, the micro-level of carbon transfer research path is a bottom-up approach, mainly using the Life Cycle Assessment (LCA). LCA is an important methodology to assess the potential environmental impacts of products, systems, or services at all stages in their life cycle. The ecosystem's carbon footprint analyzes the environmental load at the product, household, and enterprise levels. Cortés-Borda et al. (2015) investigate how to mitigate global warming by performing changes in an economy by making use of a systematic tool that combines three methods: linear programming, environmentally extended input output models, and life cycle assessment principles. In addition, a Hybrid MRIO-LCA method for hybrid processing in the MRIO and LCA models is also used to address emission transfers recently. The bottom-up approach describes data collected and processed at the micro-level, often the same as an individuals, households and business operations. One of the disadvantages of the bottom-up approach is that data collection and accounting procedures can differ from site to site, from person to person, and over time.

\subsection{Carbon Emission Transfer within Nations}

With the extensive development of international carbon transfer research, studies on the transfer of carbon emissions within nations have emerged one after another. Among them, the research in China has taken priority. China is the world's largest carbon emitter and second largest economy. There are obvious gradient differences in the economic development of various regions in China, and domestic trade also produces a large amount of emission transfers. Moreover, in order to expand domestic demand and transform the mode of economic development, cross-regional industrial transfers have become an important driving force for industrialization and urbanization. Especially in the 21st century, with the increasing pressure on environments and resources, the problem of carbon emission transfer among regions in China has begun to attract widespread attention from scholars.

From the perspective of measures of carbon transfer, the literature mainly expands from two dimensions: regional trade and regional industrial transfer. With the continuous expansion of the scale of interregional trade, the embodied carbon emissions in regional trade of products and services have become an important transmission mechanism for regional carbon transfers, and their impact on China's carbon dioxide emissions has become increasingly significant. The dimension of regional industrial transfer defines industrial transfer as an industry linkage driven by export-driven and final demand driven. Liao \& Xiao (2017) use an input-output method to construct an industrial transfer model and measure the net industrial transfer and the corresponding regional amount of net carbon transfer among consumption-driven, export-driven and final-use regions. They find that industrial transfer in the southwestern region showing carbon leakage from the pollution industries, while northern coastal areas and southern coastal areas showing carbon emission reduction effects from the clean industries.

From the perspective of the research regions of carbon transfer, the existing literature is mainly developed from two levels: regional level and provincial level. Regional carbon transfer research often divides China into eight regions: northeast, central, northwest, southwest, Beijing and Tianjin, northern coast, eastern coast, and southern coast. China's input-output tables are used to account for the total regional flows and transfers of products/services and embodied carbon emissions (Yao \& Liu, 2010). Since major industries transferred out from the coastal regions are high-carbon, high-energy-consuming, resource-based industries and related manufacturing industries, scholars have basically agreed that coastal industrial transfer and regional trade lead to increased pollution and carbon leakage of central and western regions. The central region of China shows the characteristics of the transfer station for carbon transfer from East region to West region (Liao \& Xiao, 2017). As the comprehensive consideration of the emission transfers among provinces in China is relatively insufficient, it is hard to meet the current requirements for China to decompose the carbon emission targets into provincial-level administrative regions. Pang et al. (2017) apply the input-output table to measure the carbon footprint and carbon transfer of the 12 provinces in China, and find that the three provinces of Hebei, Shanxi, and Inner Mongolia are under carbon emission pressure from other provinces. 
From the perspective of research methods, domestic research mainly draws on international carbon transfer research methods, adopts domestic input-output data, and uses input-output models to conduct research, including emissions embodied in bilateral trade (EEBT) based on single-area input-output and MRIO methods based on multi-region input-output (Pang et al., 2017). Luo (2016) uses the MRIO model to analyze carbon emission accounting and distribution of responsibility of China's provinces from three principles of producer responsibility, consumer responsibility, and technology-adjusted consumer responsibility. Zhang (2016) applies the EEBT method under the bilateral trade perspective and the MRIO method from the perspective of multilateral trade to measure the emission transfers among provinces in China simultaneously. The results show that the carbon emission coefficients calculated using the MRIO model are significantly higher than those of the EEBT method.

\section{Interregional Emission Transfer Drivers}

To study carbon emission transfer, it is necessary to find out the determinants of the transfer of carbon emissions. In recent years, interregional carbon emission transfer is recognized driven by a variety of factors: improvements in the economic development level, promotions of energy efficiency of production, changes in the industrial structure, changes in the composition of final demand, processes of foreign economic liberalization (i.e., economic openness), as well as socio-demographic trends. Most of these studies involve multiple influencing factors to examine their impact on carbon emissions. According to research methods, research on carbon transfer drivers can be divided into three categories: decomposition analysis, econometric methods, and hybrid methods.

\subsection{Decomposition Analysis}

Decomposition analysis can be applied to directly quantify the contribution of various drivers to the overall change in industrial-related carbon emissions. Decomposition analysis is generally based on environmental impact assessment models (such as the well-known IPAT identities and derived KAYA identities). To quantify the impact of different factors on change of $\mathrm{CO}_{2}$ emissions, two main decomposition methods are popular today: index decomposition analysis (IDA) and structural decomposition analysis (SDA) (Wang et al., 2017).

The analysis based on the IDA framework is widely used based on data collecting from industries and departments. Applying IDA requires that the data of the sum of industries and departments is available with a certain number of continuous years. The specific research field of IDA covers energy consumption, $\mathrm{CO}_{2}$ emissions, the relationship between energy and $\mathrm{CO}_{2}$ emissions, the relationship between energy and environment, the relationship between $\mathrm{CO}_{2}$ and economic development, and many other aspects (Lin et al., 2006; Xu \& Ang, 2013; Cansino et al., 2015). Among IDA methods, the logarithmic mean divisia index (LMDI) decomposition methods has been recognized as the preferred method and widely used (Ang, 2004). Through the analysis of continuous historical data in the above-mentioned research fields, the specific direction of conclusions of IDA is clear, and related policy recommendations is also relatively simple. IDA is thus easy for government officials and the public to understand. IDA provides an easy way to use public data and has been proven to be particularly effective in tracking energy efficiency improvements across economies. IDA is applied by energy agencies in various countries, including the United States, Canada, Australia, New Zealand, and Europe.

SDA has been used to analyze carbon emissions and energy intensity indices for a specific country or group of countries based on the regional input-output models. Based on 28 regional input-output tables of China for 2002 and 2007, Feng et al. (2012) adopt SDA to analyze how changes in population, technology, economic structure, urbanization, and household consumption patterns drive regional $\mathrm{CO}_{2}$ emissions. Dong et al. (2018) employ SDA and quantile regression to investigate the factors that drive changes in carbon emission intensity in China. The results specify that the industrial sector is the key sector for energy conservation and emission reduction. Mohlin et al. (2018) use both IDA and SDA to analyze the driving role of renewable energy in carbon emissions reduction in the United States. In the period from 2007 to 2013, US carbon emissions were reduced by approximately $10 \%$, of which $2.3 \%-3.3 \%$ emission reduction from renewable energy, $2.5-3.6 \%$ reduction from natural gas, and $0.6-1.5 \%$ reduction from nuclear energy.

\subsection{Econometric Methods and Regional Panel Data}

Compared with the decomposition analysis, the econometric method can more flexibly incorporate multiple drivers into the model according to the corresponding theory, and test whether various drivers have statistical significance for carbon emissions. However, this method cannot determine the actual contribution of various factors to carbon emissions and can only estimate the coefficient of elasticity of carbon emissions for various factors.

Some scholars have focused on the research on the driving factors of carbon emission transfer between regions, 
in particular, testing the pollution haven hypothesis and factor endowment hypothesis. Among them, most studies are based on econometric methods (Lin \& Zou, 2014), whereas their conclusions are not consistent. Zhang (2015) applies input-output models to study this issue and finds that the pollution haven hypothesis and factor endowment hypothesis can only partly explain China's interregional trade.

\subsection{Combination of Decomposition Analysis and Econometric Methods}

The main method combined decomposition analysis and econometrics is STIRPAT (Stochastic Impacts by Regression on Population, Affluence, and Technology) (Ma, et al., 2017). STIRPAT builds on IPAT/impact equation of Ehrlich and Holdren (1971): $\mathrm{I}=\mathrm{P} \times \mathrm{A} \times \mathrm{T}$, where $\mathrm{I}$ is environmental impact, $\mathrm{P}$ is population, $\mathrm{A}$ is affluence, and $\mathrm{T}$ is technology. The STIRPAT formulation transfers the traditional IPAT model from taking the logarithm form to an econometric model and can incorporate more drivers. However, this hybrid approach seems to reflect more of the characteristics of the econometric approach, which is mainly to estimate the coefficient of elasticity of carbon emissions on relevant factors.

\section{Sharing Responsibility for Carbon Emissions}

The essence of the question of who is responsible for carbon emissions, associated with the production of goods/services in countries/regions for consumption in other countries/regions, is the allocation of responsibility for emissions between the producer and the consumer. Therefore, from the perspective of allocating carbon emission responsibilities between regions, there are two basic principles: producer responsibility and consumer responsibility.

\subsection{Producer Responsibility}

The Kyoto Protocol allocates $\mathrm{CO}_{2}$ emissions to the country in which the emission occurs, called producer responsibility. The current national emissions inventories released by the United Nations Intergovernmental Panel on Climate Change (IPCC) are also generated based on this producer responsibility in which a nation is responsible for all emissions emitted within its borders, including the products it produces, the services it provides, and the $\mathrm{CO}_{2}$ emissions during energy consumption. A further principle in line with this is extended producer responsibility (EPR) that is likely to motivate countries to reduce $\mathrm{CO}_{2}$ emissions throughout the life cycles of the goods they produce (Clift \& France, 2006). The principle of producer responsibility is widely used in academic research: Chang \& Lin (1998) follow the principle of producer responsibility, distribute carbon emissions to each production department according to the final-use path in the life cycle, and calculate carbon emissions from Australia, the United Kingdom, Germany and Taiwan. Lenzen (1998) and Kim (2002) calculate carbon emissions from Australia and South Korea respectively on the basis of the principle of producer responsibility. Based on this principle, He (2010) also measures the annual direct and indirect carbon emissions during the production process of each department in China.

Although allocating emissions responsibility to the producer can motivate direct emitters to reduce emissions from production, there is no incentive for the consumer to control a significant fraction of global carbon emissions "hidden" in international trade. Peters \& Hertwich (2008a, 2008b) estimate that in 2001, roughly 23\% of energy related emissions were embodied in trade. Producer responsibility is criticized for causing carbon leakage, which occurs when a country opts to limit its own carbon emissions by importing goods or transferring high-carbon industries. By international trade and transferring high-carbon emission industries to developing countries, the carbon emissions reported by the developed country is reduced, but the total global carbon emissions increase. Furtherly, due to differences in the economic levels and structure, producer responsibility principle only considers the pollution emissions directly related to the domestic sector, resulting in the developing country as a major exporter of high-pollution, high-energy-consuming products, while the developed countries as an importer of foreign products to enjoy high standards of living and low levels of pollution.

\subsection{Consumer Responsibility}

Production serves consumption. The distribution of carbon emissions and emission reduction responsibilities for ultimate consumers has become a hot topic of research. Many scholars and research institutions advocate that a country should bear the carbon dioxide emissions caused by the products and services it consumes, known as consumer responsibility (Munkagaard \& Pedersen, 2001). Since final consumption is one of the important driving force of industrial development at the expense of environmental damage, countries of final consumption should take responsibility for the environmental costs and consequences of consumption patterns. Consumption-based $\mathrm{CO}_{2}$ inventories account for emissions from production and imports, and subtract embodied emissions exported in trade (Peters \& Hertwich, 2008b). Allocating embodied emissions to the consumer can mitigate the problem of carbon leakage. The consumer responsibility sharing mechanism seems to be more 
beneficial and fairer to developing countries, and it might help to encourage more participation from developing countries in mitigation regime (Zhou et al., 2010).

There is a growing body of literature demonstrating that consumer responsibility principle is used to calculate the amount of carbon dioxide. Using Denmark as a case, Munksgaard and Pedersen (2001) demonstrate the distinction between a production and a consumption principle to account annual $\mathrm{CO}_{2}$ emissions. They show that it has become more difficult to reach the Danish $\mathrm{CO}_{2}$ target as an increasing part of emissions from foreign demand, and then the consumer $\mathrm{CO}_{2}$ accounting principle gives additional information to decision makers. Feng (2003) suggests the benefit principle that assigns the responsibility of pollutant emissions to the driving forces behind the activities that emit pollutants rather than to direct emitters. Zhou et al. (2010) argues that a change from producer responsibility to consumer responsibility greatly influences national emissions inventories, which implies that trade adjustment to current national accounting to generate national responsible emissions accounts can be considered as a complementary policy option to help address the carbon leakage concern.

However, a shortcoming of consumer responsibility including foreign imported $\mathrm{CO}_{2}$ emissions in the national account is that no direct influence can be expected by the importing country on the technologies and fuels used abroad (Munksgaard \& Pedersen, 2001). There arises a problem of low carbon emission efficiency of exporting countries or export industries because they are carbon emission producers, rather than consumers. Moreover, emissions accounting based on consumer responsibility principle is complicated and requires massive data that is normally difficult to obtain.

\subsection{Shared responsibility}

Assigning the responsibility for carbon emissions to either full producers or full consumers should not be a binary decision, shared producer and consumer responsibility is needed (Zaks et al., 2009). Hence, several authors have put forth allocation schemes in which carbon emissions are shared between producers and consumers. The shared responsibility provides economic incentive to consumer nations to meet demand with the smallest environmental impacts and pushes producer nations to reduce the carbon emissions embodied in their producing process simultaneously.

Lenzen et al. (2007) portray the real-world that both the final consumers and their upstream suppliers play some role in causing ecological footprints and discuss a method of mutually exclusive and collectively exhaustive responsibilities to be shared by all actors in an economy. Kander et al. (2015) propose the principles of technically adjusted consumer responsibility accounting to compensate for the deficiencies of the producer responsibility and consumer responsibility. The basic idea is that carbon emissions from the product are compared with the world average carbon intensity for each sector. If the carbon emission of export products is higher than the world average, the higher part is the responsibility of the producer. Conversely, if the carbon emissions of exports are lower than the world average, and the lower part needs to be deducted from the producer to show incentives for the producer of low carbon production. Jiborn et al. (2018) proposes a new indicator - the technology adjusted balance of emissions embodied in trade - that improves on existing ideas by separating out the effects of scale and composition of trade from the effects of different technologies and energy systems.

\section{Conclusions and Implications}

\subsection{Conclusions}

The mitigation of the global carbon emissions is not only an economic issue but also a political game in a non-cooperative globalized world. Although effort commitments have thus far been made to control carbon emissions by governments, the controversy of environmental responsibility and carbon reduction has never stopped. Interregional carbon emission transfer has been the focus of the disputation.

This study provides a comparative review of the interregional carbon transfer by surveying the theoretical basis and empirical evidence from the literature. Our reading of the extant literature suggests the following conclusions:

Regional carbon transfer is mainly aroused by interregional trade and industrial transfer, including macro-, meso-, and micro-levels.

Decomposition analysis, econometric methods, and hybrid methods are used to distinguish key factors driving interregional carbon transfer.

Two extremes of allocating full responsibility for producers or consumers is arguable, the intermediate principle of shared producer and consumer responsibility may work as direct incentives to improve environmental 
behaviors of both actors.

\subsection{Implications}

Recent growth in carbon emission transfer between developed and developing countries/regions is accelerating with closer spatial economic relations. Interregional emission transfer, carbon emissions produced in one region and consumed in other regions, then has become an acute debate in the public climate change discussion, attracting the attention of academic researchers, business experts, national or local governments, and international organisations as well as. Therefore, this systematic literature review is particularly useful to gather and integrate information to provide sound theoretical foundations for incorporating interregional carbon emission transfer in building the framework of global carbon emissions. Summarizing and interpreting the research literature on emission transfer is also meaningful to facilitate more accurate policies and interventions toward regional energy cooperation and carbon reduction mechanisms around worldwide. Moreover, carbon emission transfer embodied in interregional economic ties makes the distribution of regional emission responsibility difficult. The findings of this research help policy-makers to understand the real-world implications of sharing responsibilities between producers and consumers and put the principle of common but differentiated responsibilities into practice.

While much has indeed been learned about interregional transfer of carbon emissions, there are a variety of avenues that need further research. The findings imply that the prospective research tendencies on interregional carbon transfer are as follows:

$>$ One of the most challenging problems seems to be the management of intertemporal carbon emission transfer among regions. Substantial efforts need to be put into place to build awareness about intertemporal effects of interregional transfer of carbon emissions.

$>$ As mentioned above, more attention has been paid in the extent literature to the demand-side factors in driving emission transfer. Future directions should focus in particular on supply-side factors that strengthen or weaken the existence of interregional transfer of carbon emissions.

$>\quad$ Finally, there is a general need for balancing fairness and efficiency in enhancing global mitigation actions. The distribution of carbon emission responsibilities across regions need to be further addressed, with more research to be carried out in set reasonable and consensual carbon emission targets aimed at achieving sustainable development.

\section{Acknowledgments}

This research is part of a project (Research on Measurement of $\mathrm{CO}_{2}$ Emissions Scale and Interregional Transfer in China under New Normal) funded by the Humanities and Social Science Foundation of Ministry of Education of China (\#15YJA790022).

\section{References}

Ang, B.W. (2004). Decomposition Analysis for Policymaking in Energy: Which is the Preferred Method? Energy Policy, 32, 1131-1139. https://doi.org/10.1016/S0301-4215(03)00076-4

Babiker, M. H. (2005). Climate Change Policy, Market Structure, and Carbon Leakage. Journal of International Economics, 65(2), 421-445. https://doi.org/10.1016/j.jinteco.2004.01.003

Cansino, J. M., Sánchez-Braza, A., \& Rodríguez-Arévalo, M. L. (2015). Driving Forces of Spain's $\mathrm{CO}_{2}$ Emissions: A LMDI Decomposition Approach. Renewable Sustainable Energy Reviews, 48, 749-759. https://doi.org/10.1016/j.rser.2015.04.011

Cao, S., \& Xie, G. (2007). Applying Input-output Analysis for Calculation of Ecological Footprint of China. Acta Ecologica Sinica, 27 (4), 1499-1507. https://doi.org/10.3321/j.issn:1000-0933.2007.04.029

Clift, R., \& France, C. (2006). Extended Producer Responsibility in the EU: A Visible March of Folly. Journal of Industrial Ecology, 10(4), 5-7. https://doi.org/10.1162/jiec.2006.10.4.5

Copeland, B. R., \& Taylor, M. S. (1995a). Trade and Transboundary Pollution, American Economic Review, 85(4), 716-737. https://doi.org/10.1201/9781420032628.ch8

Copeland, B. R., \& Taylor, M. S. (1995b). Trade and the Environment: A Partial Synthesis. American Journal of Agricultural Economics, 77(3), 765-771. https://doi.org/10.2307/1243249

Cortés-Borda, D., Ruiz-Hernández, A., Guillén-Gosálbez, G., \& Sales-Pardo, M. (2015). Identifying Strategies for Mitigating the Global Warming Impact of the EU-25 Economy Using a Multi-objective Input-output Approach. Energy Policy, 77, 21-30. https://doi.org/10.1016/j.enpol.2014.11.020 
Dong, F., Yu, B., Hadachin, T., \& Long, R. (2018). Drivers of Carbon Emission Intensity Change in China. Resources Conservation and Recycling, 129, 187-201. https://doi.org/10.1016/j.resconrec.2017.10.035

Dong, H., \& Geng, Y. (2012). Study on Carbon Footprint of the Household Consumption in Beijing Based on Input-Output Analysis. Resources Science, 34(3), 494-501.

Ehrlich, P., \& Holdren, J. (1971). The Impact of Population Growth. Science, 171(3977), 1212-1217.

Feng, D., Yu, B., Hadachin, T., Dai, Y., Wang, Y., Zhang, S., \& Long, R. (2018). Drivers of Carbon Emission Intensity Change in China. Resources, Conservation and Recycling, 129, 187-201. https://doi.org/10.1016/j.resconrec.2017.10.035

Feng, J. (2003). Allocating the Responsibility of $\mathrm{CO}_{2}$ Over-Emissions from the Perspectives of Benefit Principle and Ecological Deficit. Ecological Economics, 46(1), 121-141. https://doi.org/10.1016/S0921-8009(03)00104-6

Feng, K., Siu, Y. L., Guan, D., \& Hubacek, K. (2012). Analyzing Drivers of Regional Carbon Dioxide Emissions for China. Journal of Industrial Ecology, 16(4), 600-611. https://doi.org/10.1111/j.1530-9290.2012.00494.x

Fourier, J. (1824). Remarques générales sur les températures du globe terrestre et des espaces planétaires. In Annales de Chemie et de Physique, 27, 136-167.

Grossman, G. M., \& Krueger, A. B. (1991). Environmental impacts of a North American free trade agreement (No. w3914). National Bureau of Economic Research. https://doi.org/10.3386/w3914

He, Q. (2010). Measurement of Embodied Carbon based on Input-output Analysis. Forum on Science and Technology in China, 9, 112-116. https://doi.org/10.3969/j.issn.1002-6711.2010.09.019

Hendrickson, C. T., Lave, L. B., \& Matthews, H. S. (2010). Environmental Life Cycle Assessment of Goods and Services: An Input-Output Approach. Oxford: Routledge.

Jiborn, M., Kander, A., Kulionis, V., Nielsen, H., \& Moran, D. (2018). Decoupling or Delusion? Measuring Emissions Displacement in Foreign Trade. Global Environmental Change, 49, 27-34. https://doi.org/10.1016/j.gloenvcha.2017.12.006

Kainuma, M., Matsuoka, Y., \& Morita, T. (2000). Estimation of Embodied CO2 Emissions by General Equilibrium Model. European Journal of Operational Research, 122(2), 392-404. https://doi.org/10.1016/S0377-2217(99)00241-6

Kander, A., Jiborn, M., Moran, D., \& Wiedmann, T. (2015). National Greenhouse-Gas Accounting for Effective Climate Policy on International Trade. Nature Climate Change, 5, 431-435. https://doi.org/10.1038/NCLIMATE2555

Kim, J. H. (2002). Changes in Consumption Patterns and Environmental Degradation in Korea. Structural Change and Economic Dynamics, 13(1), 1-48. https://doi.org/10.1016/S0954-349X(01)00030-3

Kuik, O., \& Hofkes, M. (2010). Border Adjustment for European Emissions Trading: Competitiveness and Carbon Leakage. Energy policy, 38(4), 1741-1748. https://doi.org/10.1016/j.enpol.2009.11.048

Lenzen, M. (1998). Primary Energy and Greenhouse Gases Embodied in Australian Final Consumption: An Input-Output Analysis. Energy Policy, 26(6), 495-506. https://doi.org/10.1016/S0301-4215(98)00012-3

Lenzen, M. (2000). Errors in Conventional and Input-output - based Life-cycle Inventories. Journal of Industrial Ecology, 4(4), 127-148. https://doi.org/10.1162/10881980052541981

Lenzen, M., Murray, J., Sack, F., \& Wiedmann, T. (2007). Shared Producer and Consumer Responsibility Theory and Practice. Ecological Economics, 61(1), 27-42. https://doi.org/10.1016/j.ecolecon.2006.05.018

Levinson, A., \& Taylor, M. S. (2008). Unmasking the Pollution Haven Effect. International Economic Review, 49(1), 223-254. https://doi.org/10.1111/j.1468-2354.2008.00478.x

Li, H., \& Qi, Y., (2010). Carbon Embodied in International Trade of China and its Emission Responsibility. Chinese Journal of Population Resources and Environment, 8(2), 24-31. https://doi.org/10.1080/10042857.2010.10684973

Li, Y., \& Hewitt, C. N. (2008). The Effect of Trade between China and the UK on National and Global Carbon Dioxide Emissions. Energy Policy, 36, 1907-1914. https://doi.org/10.1016/j.enpol.2008.02.005

Liao, S., \& Xiao, Y. (2017). Pollution Industry Transfer and Carbon Transfer Space Characteristic in Midland of China. Economic Geography, 2, 132-140. 10.15957/j.cnki.jjdl.2017.02.018 
Liddle, B. (2001). Free Trade and the Environment-development System. Ecological Economics, 39, 21-36. https://doi.org/10.1016/S0921-8009(01)00215-4

Lin, B., \& Zou, C. (2014). Changes in Development Stages and China's Choice of Environmental Policies. Social Sciences in China, 5, 81-95+205.

Lin, S. J., Lu, I., \& Lewis, C. (2006). Identifying Key Factors and Strategies for Reducing Industrial $\mathrm{CO}_{2}$ Emissions from a Non-Kyoto Protocol Member's (Taiwan) Perspective. Energy Policy, 34, 1499-1507. https://doi.org/10.1016/j.enpol.2005.08.006

Lin, X., \& Polenske, K. R. (1995). Input-output Anatomy of China's Energy Use Changes in the 1980s. Economic Systems Research, 7(1), 67-84. https://doi.org/ 10.1080/09535319500000011

Luo, S. (2016). Research on China's Provincial Carbon Accounting and Responsibility Allocation. Shanghai Economic Review, 4, 45-53. https://doi.org/ 10.19626/j.cnki.cn31-1163/f.2016.04.005

Ma, M., Yan, R., \& Cai, W. (2017). An Extended STIRPAT Model-based Methodology for Evaluating the Driving Forces Affecting Carbon Emissions in Existing Public Building Sector: Evidence from China in 2000-2015. Natural Hazards, 89(2), 741-756. https://doi.org/10.1007/s11069-017-2847-x

Minx, J. C., Wiedmann, T., Wood, R., Lenzen, M., \& Owen, A. (2009). Input-output Analysis and Carbon Footprinting: An Overview of Applications. Economic Systems Research, 21(3), 187-216. https://doi.org/10.1080/09535310903541298

Mohlin, K., Camuzeaux, J. R., Muller, A., Schneider, M., \& Wagner, G. (2018). Factoring in the Forgotten Role of Renewables in $\mathrm{CO}_{2}$ Emission Trends Using Decomposition Analysis. Energy Policy, 116, 290-296. https://doi.org/10.1016/j.enpol.2018.02.006

Munksgaard, J., \& Pedersen, K. A. (2001). $\mathrm{CO}_{2}$ Accounts for Open Economies: Producer or Consumer Responsibility? Energy Policy, 29(4), 327-334. https://doi.org/10.1016/S0301-4215(00)00120-8

Pang, J., Gao, X., Shi, Y., \& Sun, W. (2017). Carbon Footprint and Carbon Transfer at Provincial Level of China Based on MRIO Model. Acta Scientiae Circumstantiae, 5, 2012-2020. https://doi.org/10.13671/j.hjkxxb.2016.0372

Peters G. P., Weber, C. L., Guan, D., \& Hubacek, K. (2007). China's Growing $\mathrm{CO}_{2}$ Emissions: A Race between Increasing Consumption and Efficiency Gains. Environmental Science Technology, 41(17), 5939-5944. https://doi.org/ 10.1021/es070108f

Peters, G. P., \& Hertwich, E. G. (2008a). $\mathrm{CO}_{2}$ Embodied in International Trade with Implications for Global Climate Policy. Environmental Science Technology, 42(5), 1401-1407. https://doi.org/10.1021/es072023k

Peters, G. P., \& Hertwich, E. P., (2008b). Post-Kyoto Greenhouse Gas Inventories: Production versus Consumption. Climatic Change, Change, 86(1-2), 51-66. https://doi.org/10.1007/s10584-007-9280-1

Qi, T., Winchester, N., Karplus, V. J., \& Zhang, X. (2014). Will Economic Restructuring in China Reduce Trade-embodied $\quad \mathrm{CO}_{2} \quad$ Emissions? Energy Economics, 42, 204-212. https://doi.org/10.1016/j.eneco.2013.12.011

Ren, S., Yuan, B., Ma, X., \& Chen, X. (2014). The Impact of International Trade on China's Industrial Carbon Emissions Since its Entry into WTO. Energy Policy, 69, 624-634. https://doi.org/10.1016/j.enpol.2014.02.032

Shui, B., \& Harriss, R. C. (2006). The Role of CO2 Embodiment in US-China Trade. Energy Policy, 34, 4063-4068. https://doi.org/10.1016/j.enpol.2005.09.010

Tobey, J. (1990). The Effects of Domestic Environmental Policies on Patterns of World Trade: An Empirical Test. Kyklos, 43(2), 191-209. https://doi.org/10.1111/j.1467-6435.1990.tb00207.x

Tyndall, J. (1859). On the Transmission of Heat of Different Qualities through Gases of Different Kinds. In Proceedings of the Royal Institution, 3, 155-158.

Wang, H., Ang, B. W., \& Su, B. (2017). Assessing Drivers of Economy-wide Energy Use and Emissions: IDA versus SDA. Energy Policy, 107, 585-599. https://doi.org/10.1016/j.enpol.2017.05.034

Wyckoff, A. W., \& Roop, J. M. (1994). The Embodiment of Carbon iIn Imports of Manufactured Products: Implications for International Agreements on Greenhouse Gas Emissions. Energy Policy, 22(3), 187-194. https://doi.org/10.1016/0301-4215(94)90158-9

$\mathrm{Xu}, \mathrm{X} .$, \& Ang, B.W. (2013). Index Decomposition Analysis Applied to $\mathrm{CO}_{2}$ Emission Studies. Energy 
Economics, 93, 313-329. https://doi.org/10.1016/j.ecolecon.2013.06.007

Yao, L., \& Liu, J. (2010). Transfer of Carbon Emissions between China's Eight Major Regions. China Population Resources and Environment, 12, 16-19. https://doi.org/10.3969/j.issn.1002-2104.2010.12.004

Zaks, D., Barford, C., Ramankutty, N., \& Foley, J. (2009). Producer and Consumer Responsibility for Greenhouse Gas Emissions from Agricultural Production - A Perspective from The Brazilian Amazon. Environmental Research Letters, 4(4), 1-12. https://doi.org/10.1088/1748-9326/4/4/044010

Zhang, Y. (2015). Interregional Trade Model from the Perspective of Carbon Emissions: Pollution Shelters and

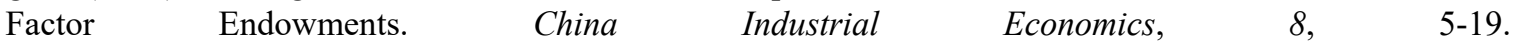
https://doi.org/10.19581/j.cnki.ciejournal.2015.08.001

Zhang, Y. (2016). Inter-Regional Carbon Emissions Transfer in China: Comparison of the EEBT and MRIO Methods. Journal of Chongqing Institute of Technology, 11, 17-27. https://doi.org/10.3969/j.issn.1674-8425(s).2016.07.004

Zhang, Z., Zhao, Y., Su, B., Zhang, Y., Wang S., Liu, Y., \& Li, H. (2017). Embodied Carbon in China's Foreign Trade: An online SCI-E and SSCI based Literature Review. Renewable and Sustainable Energy Reviews, 68(1), 492-510. https://doi.org/10.1016/j.rser.2016.10.009

Zhou, X., Liu, X., \& Kojima, S. (2010). Carbon Emissions Embodied in International Trade: An Assessment from the Asian Perspective. Institute for Global Environmental Strategies. Retrieved from https://www.jstor.org/stable/resrep00851

\section{Copyrights}

Copyright for this article is retained by the author(s), with first publication rights granted to the journal.

This is an open-access article distributed under the terms and conditions of the Creative Commons Attribution license (http://creativecommons.org/licenses/by/4.0/). 